Tempo Social; Rev. Sociol. USP, S. Paulo, 10(1): 143-163, maio de 1998.

\title{
A classe média no mundo do neoliberalismo
}

\author{
ROBERTOGRÜN
}

Resumo: O texto procura dar conta das recentes transformações na maneira como as classes médias brasileiras apreendem e dão sentido à sua vida na esfera econômica. Para isso, utiliza dados e análises de pesquisas sobre transformações em ambientes de trabalho burocráticos, construção de espaços argumentativos dos gerentes, formas tradicionais e mais recentes do pequeno comércio e sobre o também recente fenômeno do desemprego gerencial. Procura entender o problema mediante um estudo de transformações das convenções cognitivas implícitas nas formas de se entender o mundo social e seus reflexos nas vivências da esfera econômica. Da análise emerge um interessante caso de cegueira institucional, onde todas as evidências que põem em xeque a nova ordem são descartadas e onde a antiga divisão das classes médias em estratos assalariados e autônomos tem de ser repensado.

\section{Introdução}

espaço das classes médias brasileiras tem sido revolvido por mudanças freqüentes nas suas formas legítimas de ocupação. Um emprego não-manual numa repartição pública assegurado por concurso ou pistolão; duas ou três casinhas de aluguel, uma "letra de viúva" e mais um portfólio de ações da Lighte outras concessionárias de serviços públicos; um cargo de gerente numa empresa pública; o "encarreiramento" numa empresa multinacional -desde o início do século e com o suceder das gerações, a posse de cada um desses trunfos isoladamente ou em conjunto foram, em seu tempo, boas garantias de um "lugar ao sol" para quem os obtinha ou herdava.
UNITERIMOS

classes médias, neoliberalismo, sociologia econômica, convenções cognitivas, convenções econômicas.

Texto integrante da mesa redonda Para onde vai a classe média, organizada pelos GT's Trabalho e Sociedade e Educação e Sociedade, no XX Encontro Anual da ANPOCS, de 22 a 26/10/1996.

Professor do Departamento de Engenharia de Produção da UFSCar 
* Este artigo é resultado de pesquisas financiadas pela Fapesp e pelo CNPq.

Poupo o leitor da comunidade sociológica da explicação do altruísmo como uma espécie de egoísmo, típico dos circunlóquios economicistas. Por dever de ofício, indico que me inspiro mais uma vez em Douglas (1992).
Num olhar retrospectivo, todas aquelas estratégias "garantidas" de se alcançar as seguranças econômica e estatutária necessárias para caracterizar padrões de vida típicos da classe média desmancharam-se no turbilhão das mudanças sociais e econômicas. Sempre que uma delas entrava em crise, podíamos observar sua expressão na imprensa da época, através de matérias bombásticas e de impacto sobre a "crise da classe média", "os expulsos do paraíso" ou, mais geralmente, "o fim da classe média". Faltava aos analistas e à imprensa o necessário "background sociológico" para entender que se tratava de uma recriação contínua das posições médias, cada vez a partir de um substrato econômico diferente ? Ou estavam todos submetidos a um poderoso consenso que prescrevia que as formas vigentes em cada um daqueles momentos correspondiam exatamente à essência imortal da classe média? Já que a definição possível de uma situação faz parte de sua "verdade", penso que a segunda resposta é a única sociologicamente sustentável e procuro analisar a produção contemporânea de consenso que está se formando em torno de franquias, de fundos de pensão móveis e de administração da empregabilidade. Essas novidades estão sendo consideradas formas de inserção e de gestão de riscos econômicos "sistêmicas" na nova ordem "neoliberal", sendo rapidamente naturalizadas pelo consenso que se forma em torno delas. No presente trabalho enfatizarei a franquia e suas relações com as outras formas de inserção.

Os novos instrumentos de gestão segura da esfera econômica da vida das classes médias fazem parte de um novo sistema econômico de governança, no seio do qual estão sendo institucionalizados por uma convenção cognitiva. Esse resultado é possível porque eles são a expressão de um sistema classificatório compartilhado e naturalizado em nossa sociedade (cf. Douglas,1986a, p.46). A natureza humana é vista como a realização do ideal do Homo oeconomicus dos manuais de economia: os homens são seres egoístas que procuram maximizar suas utilidades, e uma boa sociedade é aquela onde os apetites inerentes à "essência do ser humano" são canalizados para promover o bem comum, independente das vontades pessoais. O comportamento oportunista é natural; esperar altruísmo por parte do próximo é o caminho mais rápido para a ruína. Portanto, o altruísta deve ser visto como alguém com "defeito de fabricação", no mínimo, um otário ${ }^{1}$. Assim, paradoxalmente, ainda que possamos encontrar comportamentos altruístas no atual momento ideológico (ou talvez o mais correto seria falarmos em "momento cognitivo", dada a robustez apresentada pelos pré-julgados), eles encontram-se de tal maneira deslegitimados, que acabam tendo de defender sua coerência através dos circunlóquios economicistas (cf. Rieder, 1990, p. 190-213).

\section{Convenções econômicas e cognitivas}

Podemos examinar o surgimento e robustecimento das novas convenções econômicas inspirando-nos no estudo de situações análogas, como aquela que surgiu quando as instituições do Ancien Régime foram substituídas pelas 
novidades que acabaram instituídas pelo efeito dos vagalhões sucessivos produzidos pela Revolução Francesa. W. Reddy (1986) fornece-nos pistas, trabalhando baseado em dois dicionários de comércio de tecidos de sucesso, que expressavam o consenso entre os negociantes nos momentos respectivos de suas aparições: o primeiro é anterior à Revolução (1723) e o segundo de 1839 . O Autor descreve-nos as diferenças que aparecem na forma de apreciação "evidentes", que o negociante avisado deveria empregar para avaliar os tecidos que mercava. No primeiro caso, numa época que a produção daquela mercadoria estava totalmente submetida ao sistema de guildas, toda a expertise residia em avaliar a qualidade e a procedência do produto, não fazendo o menor sentido uma discussão sobre os métodos de fabricação, já que esses eram apanágio da respectiva guilda (tecidos não produzidos por guildas eram tão ilegítimos/sem qualidade, que não apareciam no livro e não se concebia que um comerciante bem estabelecido trabalharia com eles). O dicionário da época (Savary) refletia essa convenção. Em 1839, o mundo tinha mudado drasticamente: o dicionário surgido do estabelecimento da nova convenção cognitiva enfatizava os métodos de produção e as matérias-primas necessárias para sua produção correta. Mais do que esse resultado bem conhecido, Reddy relata os titubeios dos interessados no interregno decorrido entre os indícios do fim da validade dos ensinamentos do primeiro dicionário e a aparição do segundo. Diante dos movimentos governamentais que indicavam o fim das guildas, os comerciantes temerosos do imenso salto no escuro que o mundo estava prestes a realizar advertiam os governos para o previsível estado de anarquia econômica e social que se sucederia: os trabalhadores, livres da disciplina imposta pela relação mestre/aprendiz, estariam disponíveis para seguir seus baixos instintos e cair em tentação. Pior ainda, já que ninguém poderia garantir a qualidade dos produtos, seria instaurado o reino da contrafação. O comércio tenderia a se desorganizar pela falta de garantia de qualidade, e com ele a nação como um todo.

Para fazer face às inquietações dos patrícios urbanos, a argumentação padronizada escorava-se nos princípios da Declaração dos Direitos do Homem: se os homens são iguais, não se pode atribuir privilégios a ninguém, nem os estatutários, nem os econômicos. Por mais interessantes e justos que os princípios pudessem parecer, eles eram muito abstratos para prevenir as falsificações econômicas e aliviar o sentimento de insegurança dos indivíduos. Entretanto, eles estavam ali para ficar. Querendo ou não, o mundo cultural em que a atividade econômica do Ancien Régime estava enraizada estava superado e nada nem ninguém poderia trazê-la de volta. As virtudes regulatórias do livre-mercado ainda não eram conhecidas, apenas tornou-se inconcebível a vida social com a manutenção dos antigos privilégios.

Estaríamos agora diante de uma situação análoga? No caso histórico examinado por Reddy, sabemos o desfecho. Falar para o nosso caso da "inevitabilidade da prevalência do neoliberalismo e da globalização" seria entregarmo-nos à forma mais tradicional do sociologismo barato: o fatalismo do provável. Mas, se a análise de Reddy foi facilitada pela certeza do resultado 
2 Cf. Fama (1980). É difícil deixar de lado a tentação de classificar a "Agency Theory" como uma continuadora moderna da "Economia Política vulgar" que tanto incomodava $\mathrm{K}$. Marx (1971, p. 453 ss.), "pecadilho" que, de alguma maneira, C. Perrow (1990) comete ao criticá-la, de maneira pertinente quanto à lógica interna, quando parece-me que o mais correto seria entendê-la como um artefato sóciocultural poderosíssimo, que fornece sentimentos de segurança, coerência e progressismo para os arautos da nova era. Mas talvez eu esteja exagerando: cf., no sentido contrário, a análise da difusão da "Reaganomics" por W. Parsons (1990), particularmente da chamada "curva de Laffer", no início dos anos 1980, onde o autor mostra a progressiva irrelevância da chancela erudita para assegurar a veracidade e operacionalidade política das "teorias econômicas vulgares", oriundas do consenso do mercado financeiro norte-americano, ao contrário do que se passou com o avanço do keynesianismo e do monetarismo "erudito" de Milton Friedman. histórico consolidado, para a nossa trocamos o conhecimento prévio do resultado pela possibilidade de examinar as operações simbólicas cotidianas que contribuem para a realização da mudança da convenção cognitiva, que parece, como no caso examinado pelo autor, igualmente abstrata, mas nem por isso menos atuante. Ela age no sentido de, para largas parcelas das classes médias brasileiras, tornar "impossível" o convívio com os constrangimentos próprios das grandes organizações. Este texto tenta indicar alguns desses passos examinando o alcance das transformações recentes das maneiras de vivenciamento das estratégias de inserção e re-inserção econômicas por que passa a classe média brasileira. Para tanto utilizo material oriundo de duas "frentes de trabalho teórico": a primeira delas trata da relação que os atuais gerentes e ex-gerentes desempregados têm com seus empregos e perspectivas; a segunda examina o robustecimento das formas "neoliberais" de inserção econômica para as classes médias. A ligação entre elas é óbvia: os indivíduos são simbólica e economicamente tangidos a abandonar a esperança de carreiras profissionais nas grandes empresas e no governo e a procurar alternativas no pequeno comércio ou indústria.

\section{As transformações no espaço social das grandes organizações}

A partir da segunda metade dos anos 1950, a gestão das grandes empresas norte-americanas caracterizou-se pela prevalência do chamado "ponto de vista financeiro" (cf. Fligstein, 1990, p. 239 e ss.). Nas duas décadas seguintes ele amadureceu, criando uma espécie de "comunidade intelectual" entre os especialistas financeiros das grandes corporações e os agentes do mercado financeiro, esses últimos, obviamente, já nascidos sob o signo da prevalência dos critérios financeiros de medição da performance empresarial. No início da atual "revolução dos acionistas", a visão financeira ganhou estatuto científico, e, portanto, "endureceu-se" como artefato cultural através da Agency Theory ${ }^{2}$. Esta, por sua vez, vendo a empresa como um "feixe de contratos", embasa teoricamente alguns dos instrumentos de gestão estratégica empresarial mais em voga atualmente: a reengenharia e a terceirização. A prevalência das duas tecnologias de gestão leva a um importante resultado: ao anunciar aos quatro ventos, numa interessante coalizão com a imprensa, que os empregos não são mais seguros e que cabe aos próprios profissionais preocupar-se com suas carreiras (ao invés da situação anterior, onde a grande empresa tomava para si a responsabilidade de prever a carreira de seus colaboradores graduados), ela rompe com as expectativas de crescimento da chamada sociedade gerencial, o mundo das grandes organizações que oferecia milhões de empregos e traçados de carreira de qualidade nos países centrais, desde pelo menos o fim da Segunda Guerra Mundial e desde o começo do século para os $\mathrm{EUA}^{3}$.

No centro da mudança de padrão atual, a novidade é a exigência do cumprimento efetivo do mandato gerencial de fazer valorizar ao máximo o retorno financeiro dos aportes fornecidos pelos acionistas, que esta sendo popularmente chamada de "Revolução dos acionistas". Esse "mandato imperativo" 
contrapõe-se cognitivamente ao managerial capitalism, visto como um sistema onde os diretores prepostos das empresas teriam adquirido um grau de liberdade tão grande, que eles privilegiariam seus interesses particulares em detrimento dos acionistas. Numa outra versão, tratar-se-ia do retorno à opção de "lucro máximo no curto prazo" em detrimento do "crescimento a todo custo" que seria a estratégia típica dos diretores profissionais ávidos de mais poder ${ }^{4}$. Diante das incertezas postas pela existência das duas maneiras de se medir o desempenho das empresas, surge a questão da mensuração da performance das empresas que visam lucro. Numa aproximação simplista, lucro é simplesmente "o resultado (diferença entre receitas e [custos + despesas]) apurado segundo os princípios contábeis geralmente aceitos". Esse resultado seria apurado pelos contadores da empresa e ratificado ou corrigido pelos auditores externos. Mas esse mundo idílico da contabilidade também desmancha-se no ar. Os experts contábeis estão cada vez mais contestados no próprio mercado de capitais ${ }^{5}$. Uma vez que a estrutura das carreiras dos auditores independentes é enormemente afunilada, eles seriam obrigados a manter ótimas relações com os clientes, que poderão tornar-se seus futuros empregadores, já que a maior parte dos auditores é obrigada a trocar de emprego no meio de sua carreira, não sendo admitido o trânsito entre firmas de auditoria. Evidentemente, esse constrangimento opera sobre a própria vontade de apontar problemas nas demonstrações contábeis que são oferecidas à sua perícia.

Tendo indagado sobre a prevalência dessa tendência internacional no Brasil, fomos informados por auditores e ex-auditores engajados nas grandes empresas do setor que entre nós essa tendência é ainda mais acentuada, já que muitos dos cargos mais importantes nas empresas de auditoria internacionais aqui instaladas são ocupados por indivíduos vindos das matrizes, afunilando ainda mais as pirâmides dos mercados internos de trabalho. Portanto, nenhum espanto diante das recentes reclamações da imprensa sobre a talvez conivência das empresas de auditoria externa com as administrações das empresas nos casos Banespa/Eletropaulo, Nacional e Econômico...

Mas os problemas da mensuração não se restringem àqueles oriundos dos constrangimentos nas carreiras dos contadores. Sociologicamente, a contabilidade é vista mais genericamente como um processo de legitimação (cf. Fligstein, 1990; Meyer, 1994). Cada época do campo empresarial gera as suas próprias formas de medir o lucro, em geral incompatíveis com as anteriores e com as posteriores. Como conseqüência, em momentos de transição como os que passamos atualmente, convivem diferentes instrumentos de mensuração, que permitem a diferentes organizações, ao mercado financeiro, ou mesmo subgrupos dentro das organizações, considerarem que "vão bem" ou que "vão mal", sem correspondência necessária com a opinião dos agentes externos ${ }^{6}$.

Para os fins deste texto, devem ser ressaltados os efeitos dessa "plasticidade" sobre a avaliação de chances - de seguir carreira ou de associar-se como franqueados ou fornecedores de serviços terceirizados - que os agentes da amostra efetuam nas suas relações com as grandes empresas. Essa
Até pouco tempo atrás, era "evidente" que o mundo gerencial estaria encolhendo na estabilidade oferecida, no tamanho e na remuneração de seus membros. Hoje começam a aparecer dados nos EUA que contradizem essa visão. Ver a respeito: Swinnerton \& Wial (1995); seguido de controvérsia: Diebold \& Neumark \& Polsky (1996); e tréplica: Swinnerton (1996). Fica o registro da possível decalagem entre a apreciação subjetiva da situação de emprego para gerentes e a situação "objetiva”, até não aparecerem sinais de consenso entre os economistas (afinal, dizem que a economia é uma ciência exata).

4 Ver Useem (1993). Estamos certamente diante de uma tentativa de inversão do fenômeno que J.K. Galbraith popularizou como o "poder da tecnoestrutura" (cf. Galbraith, 1982, cap. 6).

5 Uma análise sociológica desse processo de deslegitimação pode ser encontrada em Montagna (1990).

${ }^{6}$ Uma visão parcialmente interna das dificuldades por que passa a profissão no momento, produzida pelos propugna- 
dores da "contabilidade crítica" - professores universitários da disciplina em situação de vanguarda intelectual pode ser encontrada em Hopwood \& Miller (1994). Uma outra visão das dificuldades de se atingir a objetividade na contabilidade, no espírito da nova Antropologia da Ciência, em Porter (1995, p. 89-112).

A situação "lógica" brasileira era análoga à francesa, descrita por P. Bourdieu e L. Boltanski (1976).

8 Mesmo internamente às empresas privadas, os diversos grupos ascendentes que disputavam posições com outros já estabelecidos tentavam rotular de "funcionários" seus oponentes, na evidente intenção de associálos aos membros do setor público da economia e assim desvalorizá-los por uma espécie de "efeito de halo" (cf. Grün, 1985). plasticidade da avaliação das performances aumenta o alcance das estratégias não-diretamente econômicas de legitimação das empresas, complexificando, em muito, a relação das empresas com os órgãos de legitimação, tais como a imprensa de negócios e a própria academia.

\section{O Brasil na modernidade}

Os ecos dessa situação chegam rápido ao Brasil, com o anúncio de processos de enxugamento organizacional que se repetem monotonamente desde o início de 1990. Surge daí a questão da propagação de rumores negativos e a (super-)estimação subjetiva das probabilidades de que "isso pode acontecer comigo". Na falta de indicadores seguros sobre o que está "realmente acontecendo" na empresa ou no ramo em que nossos agentes trabalham, a percepção genérica de que vivemos num mundo organizacional em contração, reiterada por todos os meios de comunicação, acaba substituindo as avaliações mais circunstanciadas sobre empresas e ramos de negócios específicos (cf. Einhhorn \& Hoggarth, 1985). E é realmente notável o fenômeno da debandada dos agentes que entrevistamos até o momento: mesmo os que procuram o re-emprego em grandes empresas já imaginam sua nova situação como muito mais instável do que a anterior, imaginando-se já como poupadores agressivos de parcelas significativas de seu (talvez-) futuro salário e preparando-se - por meio da realização de cursos de aperfeiçoamento, da renovação e manutenção de laços profissionais externos e da "constante busca de emprego ainda que o atual seja satisfatório" - para enfrentar com mais chances uma futura situação de desemprego. Reparemos que não se trata mais dos tradicionais "prestar mais atenção na política interna da empresa para não ser pego numa armadilha" ou "dedicar-se com mais afinco a conhecer os segredos do negócio da nova empresa", ou "apresentar provas cada vez mais fortes de dedicação e lealdade" que víamos em outras épocas.

\section{O formato das mudanças}

A mudança dos sistemas simbólicos pode ser apresentada através da sucessão de pólos de significado positivo/negativo que se sucedem, conforme a figura 1 abaixo. Podemos situar o fim dos anos 1960 e início dos 70 como um período onde, tipicamente, a grande empresa (sem distinção entre as privadas e as estatais) era vista positivamente como "aberta", racional porque instrumentava a lógica de seus administradores profissionais, encarnando o progresso econômico, e contraposta à pequena empresa, que era vista como intrinsecamente negativa, "fechada", irracional porque existia apenas para satisfazer a lógica pessoal ou familiar de seus proprietários, inimiga do progresso ${ }^{7}$ etc.; no fim dos anos 70 a contraposição muda, aparecendo um pólo positivo representado pelo setor privado da economia, que aparecia necessariamente contraposto ao pólo estatal $^{8}$, esse último recebendo a carga negativa e sendo responsabilizado pelas 
mazelas do país. A passagem de $t_{0}$ para $t_{1}$ pode ser ilustrada pelo ataque que os meios de comunicação realizaram contra o setor público da economia a partir do fim dos anos 1970. E, finalmente, nos anos 90 assistimos à consolidação de uma outra polarização, agora entre o pólo dos “empreendedores", englobando os homens de iniciativa, em geral no setor privado e em pequenas unidades de negócios (ou grandes, mas com pouco staff), que se contrapõe ao pólo negativo dos "burocratas", que poderiam ser encontrados indistintamente no setor público ou privado da economia.Um ponto a ressaltar sobre as mudanças na passagem de $t_{1}$ para $t_{2}$ é que em $t_{2}$ a polarização aparece entre indivíduos e não mais entre organizações, como nos "tempos" anteriores, abrindo algum espaço simbólico para tentativas de aggiornamento do setor público. De uma maneira geral, como se pode ver, fechamos o círculo, com a inversão do sentido associado à "pequena empresa" no início do período.

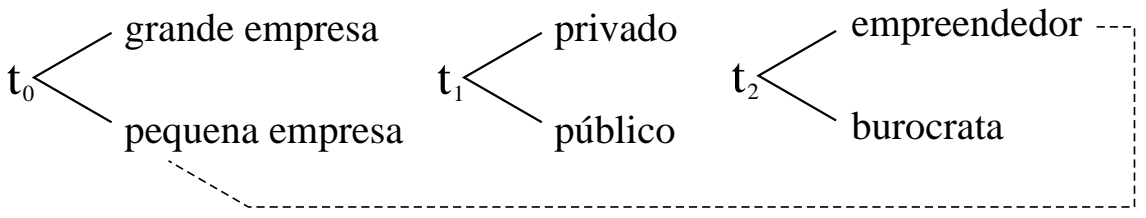

Em termos das concepções gerais de sociedade e de "contrato social implícito", podemos, usando o mapa cultural sugerido por Mary Douglas (fig. 2), falar da passagem de um mundo econômico tipicamente assentado sobre a idéia de sociedade hierárquica, com obrigações de reciprocidade que garantem a percepção da sociedade, ou, mais precisamente, das organizações que dela fazem parte como sendo justas e que, portanto, as estabilizam ${ }^{9}$ (quadrante " $C$ " da figura) para um outro mundo, individualista, onde o empreendedor merece todas as recompensas, onde "quem não se arrisca, não petisca" e onde o próprio conceito de organização é cognitivamente complicado (quadrante " $A$ ") ${ }^{10}$. Nessa passagem, saímos de uma situação onde o indivíduo, "vestindo a camisa da empresa", trabalha duro hoje, esperando (implicitamente, tendo direito) uma recompensa no futuro, para outro tipo regulação, onde "o quê você merece hoje, você recebe hoje", sem comprometimentos de longo prazo. Evidentemente, subsistem indivíduos (quadrante "B") e organizações (quadrante "D”) com outras características, mas que têm dificuldades de manter legitimidade face ao mundo circundante. De uma maneira geral, o esquema de Douglas sugere que, dado que o quadrante "A" não assegura estabilidade para a organização social, provavelmente estamos diante de uma ofensiva ideológica que desembocará simplesmente num outro tipo de sociedade hierárquica, só que estabilizada por um outro princípio de justiça/reciprocidade.

Sobre as razões da prevalência dessa "máquina de pensar", a pista geracional parece ter forte poder explicativo. Em diversos campos que pesquisamos (gerentes, profissionais de recursos humanos, líderes sindicais, jornalistas), a adesão ao novo credo parece ser uma marca geracional que coesiona os desafiantes da esfera estudada (evidentemente, segundo as possibilidades
1. os pólos de significado

9 Esse princípio de justiça/reciprocidade/ hierarquização poderia ser, por exemplo, o caso de uma organização que justifica sua hierarquia pelo conhecimento e, ao oferecer treinamento e oportunidades de aprendizagem em geral para todos os seus membros, concede a todos a chance de aumentar os seus conhecimentos e, portanto, de galgar postos na empresa. Ver Douglas (1996, p. 43 ss.) e Goodman (1978, esp. p. 10 ss.).

${ }^{10}$ No mundo dos empreendedores individualistas, toda dinâmica é produzida pelos atores com suficiente força de vontade e, nesse caso, as organizações são vistas como causadoras de dificuldades que impedem a maximização do resultado agregado da ação dos empreende- 
2. O "mapa cultural" Fonte: M. Douglas: "Thought Styles", Sage (1996), p. 43 (ligeiramente adaptado).

dores existentes na sociedade. Sobre a lógica cognitiva desse mundo, muito próxima daquela que inspira o conservadorismo norte-americano atual, ver Lakoff (1996, sobretudo p. 94; 181-183).

${ }^{11}$ Para o primeiro caso, cf. Grün (1993); para o segundo, ver Zilbovicius \& M., Ferro, J.R. \& Grün, R (1986).

expressivas de cada uma delas). Por exemplo, entre o pessoal de recursos humanos, na discussão da imputabilidade individual dos custos das greves, enquanto a "velha guarda" insistia na necessária manutenção do espírito paternalista da C.L.T., entendendo os operários "de base" participantes dos movimentos como inocentes úteis, os seus desafiantes mais novos frisavam a necessidade de "tornar o operário consciente de suas faltas" através de punições rigorosas. Mesmo no movimento sindical, na discussão das táticas a serem adotadas durante uma greve, os líderes mais antigos insistiam na necessidade de se construir a coesão do coletivo, enquanto seus êmulos mais novos pensavam num processo de mobilização que insistia nos benefícios econômicos diretos dos operários, considerados como indivíduos ${ }^{11}$. Ao que essas pesquisas indicam, estamos diante de uma "guerra cultural", onde nas diversas variantes, os jovens que procuram antecipar a ocupação dos lugares que ainda estão nas mãos dos mais velhos lançam mão de linhas de argumentação sincrônicas e que imputam ao indivíduo a responsabilidade pela sua situação, que são típicas do quadrante "A". Correlativamente, eles tentam desvalorizar os méritos passados de seus concorrentes mais velhos, os quais, por sua vez, justificariam sua proeminência hierárquica numa lógica argumentativa típica do quadrante " $C$ ". Entretanto, fica a sugestão de Douglas registrada no parágrafo acima, que nos permite inferir que o furor anti-burocrático atual só durará até os atuais fundamentalistas sentiremse seguros nas posições conquistadas e daí em diante passarão a tentar justificar sua proeminência nos méritos passados e tenderão para o quadrante " $\mathrm{C}$ ".

\section{Isolamento cultural \\ B}

\begin{tabular}{|c|c|}
\hline $\begin{array}{l}\text { Isolamento por escolha ou compulsão, } \\
\text { literalmente sós ou isolados em } \\
\text { estruturas complexas. } \\
\text { (valores ecléticos) }\end{array}$ & $\begin{array}{l}\text { Grupos fortemente integrados com } \\
\text { estrutura complexa - hierárquica com } \\
\text { obrigação de reciprocidade. } \\
\text { (organizações "tradicionais" - antigas } \\
\text { e modernas) }\end{array}$ \\
\hline $\begin{array}{l}\text { Estrutura fraca, incorporação fraca. } \\
\text { (individualismo competitivo; mundo } \\
\text { dos empreendedores) }\end{array}$ & $\begin{array}{l}\text { Grupos fortemente integrados com } \\
\text { estrutura fraca. } \\
\text { (seitas igualitárias, mas também certas } \\
\text { empresas modernas: de consultoria ou } \\
\text { do chamado "capitalismo carismático" } \\
\text { - Avon, Amway etc.) }\end{array}$ \\
\hline
\end{tabular}

A

\section{Individualismo ativo}

A literatura internacional começa a dar conta das conseqüências da nova situação, em especial, da quebra do contrato implícito de "lealdade recíproca" entre a grande empresa e seu "colaborador graduado" por meio de textos dirigidos a dirigentes de empresas e gerentes passíveis de serem atingidos pela vaga de demissões, mas caucionados por recomendações de autores 
consagrados no mundo sociológico norte-americano, como R. Kanter e B. Bluestone $^{12}$. Eles apresentam a nova situação para o gerente insistindo nas suas virtualidades positivas: a antiga situação de segurança gozada nas grandes empresas é associada à idéia popular de burocracia, de trabalho maçante, previsível, pouco enriquecedor e contraposta à nova situação, onde o indivíduo teria chances de fazer desabrochar todas as suas possibilidades, onde o desafio de cada nova situação propiciaria um maior enriquecimento pessoal, onde a instabilidade no emprego seria benéfica, pois forçaria o indivíduo a questionar-se sistematicamente, investir em novas qualificações, enfim, tornar-se mais aberto e flexível, com repercussões positivas em sua vida privada.

De maneira um pouco hilariante para quem acompanhou a evolução dos sistemas simbólicos utilizados pelos gerentes do setor privado nos últimos 15 anos, saímos de uma situação onde os gerentes do privado haviam conseguido colar a pecha de "burocratas" para a maior parte dos administradores do setor público (num processo bastante complexo, é claro, onde convergiram os interesses de vários grupos de agentes) e chegamos atualmente a uma configuração, onde o conteúdo do trabalho dos gerentes do setor privado é considerado em princípio, como "burocrático", e instantaneamente desvalorizado.

E finalmente, um neologismo começa a freqüentar a literatura e as conversas da moderna administração de recursos humanos: aparece o termo "empregabilidade" - uma das principais funções da nova administração de recursos humanos seria a de treinar continuamente os empregados da empresa, de forma que, uma vez tornados "redundantes" na empresa, eles possam conseguir novo emprego rapidamente. Essa nova atividade, ao lado do nosso já conhecido out-placement, constituiriam-se na resposta empresarial às dificuldades de se manter a lealdade dos empregados nos tempos do downsizing e da terceirização. Podemos adiantar que, embora a literatura sobre administração de pessoal já fale há algum tempo do out-placement e começe a falar na empregabilidade, nenhum dos membros de nossas amostras obteve qualquer uma dessas compensações quando foi demitido do seu último emprego. Essa discrepância faz-nos pensar que os novos instrumentos de suavização do choque do desemprego ainda estejam na sua fase de "retórica", funcionando mais como instrumentos de relações públicas das empresas em relação à mídia do que propriamente como "ferramentas gerenciais". Mas é provável que num momento próximo e/ou mais necessário, a atividade torne-se uma prática efetiva, já que, nessa zona do mundo econômico, é notável a rapidez com que a criação e a identificação do problema gera o aparecimento de um novo espaço social, onde se produzem especialidades e especialistas.

A literatura citada acima pensa a situação de maneira simplória: no antigo mundo dourado, os gerentes teriam sido colaboradores felizes das grandes empresas, num contrato tácito de longo prazo, e essa relação quase nunca teria sido perturbada. Nas minhas pesquisas anteriores (cf. Grün, 1995), os gerentes, principalmente os membros das novas gerações, procuravam incessantemente maneiras de se libertarem da homogeneização das grandes or-

${ }^{12}$ Destaco Heckscher (1995); e Johansen \& Swigart (1994). 
ganizações, vislumbrando a possibilidade do estabelecimento por conta própria como consultores. Ainda que essa alternativa não se concretizasse para a maioria das amostras, ela era sempre lembrada como uma boa alternativa para o futuro dos agentes entrevistados. Essa discrepância com a literatura sugere que podemos estar diante de uma reconstrução do passado, necessária para ressaltar, em termos cognitivos, as dificuldades da nova situação de emprego. Mas, para entender a sua vitalidade, é necessário dizer que o "novo mundo" fala alto para o imaginário dos gerentes: é uma espécie de "canto da sereia", manipulando sua ambigüidade em relação à lealdade e seus antigos desejos.

\section{Ataque e defesa}

${ }^{13}$ Sobre o cotidiano gerencial nas grandes empresas assim concebidas, ver Jackall (1988). Uma interessante avaliação crítica dos pressupostos da idéia de que "organizações menores são diferentes e mais fáceis de serem controladas" pode ser encontrada em Douglas (1986b, p. 21 ss.).

${ }^{14}$ Mas o sentido do material exposto pela imprensa não é unívoco: aparecem matérias críticas em relação à reengenharia, embora em muito menor quantidade. Se pensarmos essa situação face ao processo de difusão de outros "hits" organizacionais, verificaremos uma importante diferença: Administração por objetivos, orçamentos base-zero, CCQs, TQC, todas essas siglas tiveram um enorme período de propaganda apenas positiva, antes de começarem a aparecer suas mazelas. Não acontece a mesma coisa em relação à reengenharia, talvez por causa da associação imediata que se faz entre essa ferramenta organizacional e a dispensa maciça de empregados, que, por
Mas, apesar do ataque coordenado do mercado financeiro e de seus "agentes" internos das organizações, da imprensa e da academia, a sociedade gerencial resiste de alguma forma, mostrando que a antiga idéia que representava a grande empresa como uma espécie de comunidade onde os gerentes tinham droit de cité, desde que "vestissem a camisa", não está morta. Podemos observar essa sobrevivência em diversas frentes. Na verdade, as virtudes da reengenharia, sobretudo por meio do seu corolário, o downsizing, vêm sendo objeto de crescentes impugnações, mesmo na imprensa de negócios. Podemos mesmo apontar uma disputa entre dois projetos de modernidade organizacional: aquele baseado no TQC (Controle Total da Qualidade) e o projeto baseado na Reengenharia, que refletem, dentro das organizações, as possibilidades polares do destino da sociedade gerencial. A prevalecer o primeiro projeto, as organizações adotarão processos de aggiornamento incrementais, num processo de aperfeiçoamento contínuo onde a própria "tecnoestrutura" define os rumos de sua modernização. Assim, a estrutura das organizações continuará sendo guiada pelo espírito gerencial. Já a prevalência da segunda possibilidade, onde predomina a utilização de mecanismos de controle "macro", inspirados na Agency Theory, que devem alinhar os interesses dos gerentes com os dos acionistas mediante incentivos e penalidades diretamente econômicos e de curto prazo, indicará o controle da razão financeira (principalmente de seus portadores) e a subordinação da sociedade gerencial àqueles desígnios. No esquema ideal, a grande empresa é dividida "teoricamente" em unidades contábeis pequenas, que são monitoradas na sua lucratividade como se fossem empresas independentes, devendo produzir lucros compatíveis com seu capital estimado, caso contrário elas devem ser vendidas e o resultado apurado pela venda empregado em alguma aplicação que garanta pelo menos o lucro mínimo esperado. O pressuposto é de que as pequenas unidades são mais fáceis de serem controladas, tanto pelo preposto em relação a seus subordinados diretos, quanto na relação entre a administração central e o gerente que ela indica ${ }^{13}$.

Podemos mesmo dizer que estamos diante de um conflito simbólico que corta toda a sociedade. Interessantemente, ele apareceu e teve seus significados e instrumentos desenvolvidos principalmente no espaço 
organizacional. Muito além do espaço que estamos analisando, é evidente a importância de seu desfecho para o futuro da relação entre sociedade e Estado em sua generalidade, influenciando toda a ação estatal e o sentido das intervenções privadas na esfera pública.

O conflito começa a se evidenciar em diversos espaços. Ele aparece evidente no material que coletamos nas publicações de negócios e na grande imprensa brasileira (Exame, Gazeta Mercantil, Folha de S. Paulo, Estado de São Paulo) e ecoa nos discursos de nossos entrevistados. Grosso modo, aparece na amostra a idéia da incompatibilidade entre os dois projetos - que muitas vezes são vendidas como as "duas fases de um mesmo projeto" pelas empresas de consultoria ávidas de novas encomendas -, embora com muita dificuldade na sua vocalização plena. Os ex-gerentes sentem-se traídos, já que muitos deles tornaram-se propagandistas entusiastas dos programas de TQC, que enfatizavam justamente a canalização do entusiasmo de todos os "colaboradores" da empresa no sentido da melhora contínua dos diversos processos organizacionais, reiterando nas suas esferas de percepção o antigo contrato de "lealdade à toda prova versus garantia de emprego e carreira"; para depois virem-se "jogados às traças" pelo downsizing. A maior parte do material coletado na imprensa, que se inspira justamente nas empresas de consultoria, repete a idéia da compatibilidade organizacional entre os projetos, "desarmando" nossos agentes e inibindo o desenvolvimento lógico de suas observações ${ }^{14}$. Examinar as linhas de força simbólicas e materiais que se formam em torno dessa definição do "melhor futuro" das organizações, entre elas o Estado, é uma tarefa sociológica que dificilmente pode ser relativizada. Sócio-logicamente, o próximo passo da análise deve ser o exame do papel de órgãos de fomento na criação da nova pequena burguesia e a relação/inspiração da atuação desses órgãos com o pensamento acadêmico dominante ${ }^{15}$. Seguindo os passos de Bourdieu, a conclusão lógica dessa análise poderá levar-nos a um estudo mais geral sobre a complexificação dos mecanismos de poder na sociedade brasileira atual, onde os portadores dos diversos tipos de poder (econômico, cultural, político, social) tem sua ação cada vez mais dependente dos portadores das outras formas, num processo de entreescoramento que aquele Autor chama de "allongement des circuits de légitimation" (cf. Bordieu, 1989, p. 548).

\section{Velho e novo pequeno comércio}

E como os pequenos comerciantes entram nesse "admirável mundo novo"? Aparentemente por meio da franquia, mas só aparentemente. Está firmemente estabelecido que a nova sociedade é aquela do "conhecimento" e o pequeno comerciante tradicional é o "homem prático" por excelência: portanto, não haveria lugar para mais esse "dinossauro". Entretanto, pesquisando um universo "paralelo" - pequenos empreendedores de origem armênia, atuando no setor de calçados na cidade de São Paulo (cf. Grün, 1992) - pudemos registrar uma situação onde os jovens mantinham-se na especialização funcional inaugu- sua vez, também é notícia. Uma vez que Exame é dirigida para o público gerencial como um todo e Gazeta Mercantil mais voltada para o pessoal da mercado financeiro, não é por acaso que o tema parece muito mais presente na primeira publicação do que na segunda. Mas, de alguma forma, esse questionamento na imprensa de negócios é mais do que compensado pela sua apreciação positiva na imprensa não-dirigida, onde a moda gerencial é vista como uma espécie de "santo remédio para todos os males". Seria interessante verificar se há conflitos geracionais análogos nos órgãos da imprensa que dão cobertura mais favorável à reengenharia, o que indicaria paralelismo entre os dois campos.

${ }^{15}$ Procurei ordenar a ação desses fatores numa análise sobre as estratégias de legitimação das empresas do setor de papel e celulose e do impacto dessas estratégias nas relações com a imprensa de negócios, com a academia e com os órgãos de financiamento. Cf. Grün (1994). 
${ }^{16} \mathrm{O}$ conceito de double bind aparece constantemente na obra de Elias e de Bourdieu. Acredito que sua formulação mais rigorosa, atentando tanto para as conseqüências sociológicas quanto as psicanalíticas, é aquela exposta em Gilman (1986). rada por seus ancestrais e, diante da sociedade, eram compelidos a adotar uma situação ambivalente em relação aos valores do sistema escolar: se de um lado eles tinham a obrigação social de prosseguir seus estudos até o terceiro grau, obtendo um diploma de nível superior, tornado praticamente obrigatório para a apresentação do indivíduo nas interações sociais mais amplas (mercado de casamentos, relações com fornecedores, com bancos ou mesmo com empregados graduados); por outro lado, a qualidade desse diploma importava pouco, já que naquele ambiente considerava-se que o essencial da capacitação do empreendedor dar-se-ia através do engajamento precoce na atividade econômica tradicional da colônia. Como consequiência, os jovens daquela amostra acabavam matriculando-se em escolas noturnas privadas de Administração ou Economia, pertencentes a grupos educacionais de reputação pouco expressiva. Mas, mesmo neste caso, a relação mais direta com o conhecimento formal é complexa: os relatos aparecem recheados de situações de conflito geracional, que opõem a sua "maneira moderna" de gerir os negócios da família - não só os econômicos, mas também os emocionais - aos métodos "tradicionais, mas que sempre deram certo" de gestão empregados pelos seus pais na condução dos diversos negócios. Esses "armênios da nova geração" estão assim vinculados parcialmente ao mundo da economia moderna - e sujeitos as suas seduções ideológicoexistenciais - mediante uma variação da situação clássica de constrangimento double bind: diante de seus colegas "estudiosos", eles afirmam a irredutibilidade dos conhecimentos práticos adquiridos na sociabilidade primária da sua etnia; perante seus pais e transmissores do savoir-faire e da cultura étnica, eles apresentam-se como portadores do know-how da administração científica e, portanto, como os mais aptos, no interior da família, a tomar conta e a direcionar as suas atividades econômicas, com todos os benefícios que o recebimento precoce das heranças lhes pode trazer ${ }^{16}$.

Uma primeira apreciação poderia fazer-nos pensar que os membros das classes médias assalariadas, entrando para as camadas auto-empregadas da sociedade, iriam adotar o padrão que acabamos de descrever. Entretanto, a socialização anterior dos membros da amostra atual, onde o investimento escolar é central, certamente ajuda a produzir uma identidade diferenciada em relação aos pequenos empreendedores tradicionais, mesmo os das "novas gerações". De fato, o novo tipo de pequeno empresário liga-se à grande empresa por uma série de laços, sem com isso perder a auto-imagem de "independente". A própria percepção de que os "ativos intangíveis" - a pesquisa de mercado sistemática que estabelece os bons pontos de venda e tipos de clientelas, a necessidade de acompanhamento das atividades do franqueado para se conseguir uma garantia de qualidade, o valor da marca como fundo de comércio - vendidos pelos franqueadores são bens escassos que merecem seu preço já é uma prova da influência exercida pela maneira gerencial de ver o mundo. A aparente continuidade "objetiva" entre o novo pequeno empreendimento personificado na franquia e os pequenos comércios e indústrias tradicionais mascara uma diferença de percepção que deve ser considerada em vários eixos. O primeiro deles, e o 
mais importante, é estético: nossos entrevistados no negócio da franquia acham que são evidentes as diferenças entre seus negócios e "a padaria do português", ou a "lojinha do turco", mesmo quando, aos olhos do pesquisador, a continuidade, inclusive de clientela, parece flagrante ${ }^{17}$. Se acompanharmos Bourdieu, estamos aqui diante de estratégias de distinção bastante explícitas (cf. Bordieu, 1979), onde o grupo que estamos analisando faz absoluta questão de marcar suas diferenças justamente com seus vizinhos mais próximos na estrutura social. Se quisermos ser mais radicais, podemos aceitar a sugestão de Douglas sobre o caráter profundamente revelador das manifestações de desgosto ou de nojo. Acompanhando a Autora, a situação que descrevemos revela uma verdadeira situação de guerra cultural, onde o nosso grupo só existe cultural e socialmente por oposição àquele assinalado de forma negativa. Nesse caso, considerar as semelhanças "objetivas" mais importantes do que as diferenças "subjetivas" significaria perder de vista a lógica da invenção social, onde o magnetismo que atrai os atores para as novas formas de inserção é produzido justamente pela necessidade social de distinguir-se e, portanto, de dar sentido à vida (cf. Douglas, 1996, p. 50 ss.).

Tudo assim indica que o acesso a um léxico moderno para expressar as circunstâncias da atividade econômica (do marketing, das finanças e da qualidade) ocupa um lugar importante entre os produtos comercializados pelos franqueadores, conferindo aos franqueados uma legitimidade importante diante deles mesmos e de suas redes de relações sociais. Essa faceta pouco explicitada do produto franquia, conferindo aos franqueados a aura socialmente essencial de "modernos", de indivíduos inseridos num tipo de atividade econômica que se distingue do "português da padaria" ou do "turco da lojinha", responde assim por grande parte de seu apelo comercial. Portanto, nãoé por acaso que o perfil dos adquirentes de franquias que começa a se esboçar de nosso trabalho de campo registra uma forte presença de ex-gerentes ou familiares próximos de gerentes profissionais em atividade, que acumularam o capital necessário para dar início à empreitada a partir da atividade do primeiro. Ainda que nossos dados não permitam afirmar categoricamente esta tendência, podemos dar voz a um especialista: “Até há alguns anos, as franquias eram compradas por executivos para a mulher ou para os filhos. Hoje, é o próprio executivo - que está deixando o cargo em busca de uma nova atividade - que entra no setor" (Cherto, M., Folha de S. Paulo, 26/06/94, p. 9-2).

Um outro ponto de distinção entre a franquia e o pequeno negócio tradicional é a questão da caracterização propriamente econômica dessa nova forma. Colocando para dialogar colegas economistas especializados em organização industrial com colegas administradores especializados em mercadologia e distribuição, pudemos constatar que o negócio da franquia é visto pelos membros do primeiro grupo como levando as pessoas nele engajadas a uma especialização em franquias, quaisquer franquias, independentemente do produto ou serviço a ser comercializado. Nesse caso, os novos comerciantes passariam a desenvolver sobretudo uma boa percepção
${ }^{17}$ Em Negócios \& famílias (Grün, 1992), os membros das novas gerações de comerciantes de calçados de origem armênia julgavam que o fato de lidarem com uma clientela "de shopping" os distinguia positivamente de seus pais, que caracterizar-seiam por estabelecer seus pontos comerciais em zonas chamadas "de combate", lidando com clientelas de baixo poder aquisitivo. Embora a questão da franquia não estivesse em evidência naquele momento, os membros da "jovem guarda" ressaltavam que eles acumulavam os conhecimentos tradicionais de seus pais com os da administração científica, donde podemos inferir que eles também atribuiriam pouco valor aos produtos intangíveis ofertados pelos franqueadores. 
${ }^{18}$ Dois estudos sobre o comportamento da imprensa de negócios, que estou realizando/ realizei juntamente com meus alunos de mestrado (respectivamente sobre a difusão de métodos participativos de organização do trabalho e sobre o Controle Total da Qualidade) também demonstram a total prevalência de notícias que podemos considerar positivas sobre as novidades organizacionais em questão. Esse estilo de divulgação contrasta com as posições constatadas dos órgãos da imprensa internacional em que os jornalistas brasileiros entrevistados dizem se mirar (principalmente as revistas Business Week e The Economist). Ver também a nota 12 acima. dos riscos e vantagens de cada tipo de contrato de franquia, reaplicando seus excedentes em novas franquias. Já os colegas administradores vêem a franquia como um começo de especialização do novo comerciante no ramo do negócio em que a franquia foi aberta. Nesse caso, por exemplo, o franqueado num negócio de fast-food, tendo realizado lucros suficientes na sua primeira investida comercial, deveria abrir um novo negócio para si próprio no mesmo ramo de fast-food, só que, nesse segundo momento, sem precisar da assistência do franqueador e, correlativamente, sem precisar pagar os royalties da marca consagrada. Reparemos nas conseqüências dessa diferenciação: a prevalência do primeiro tipo de empreendedor assinalaria que a franquia representa uma novidade perene na constituição da nossa nova pequena burguesia - estaríamos diante de um novo comerciante em "estado puro", pouco engajado nas sutilezas do produto que merca, adotando diante de seu negócio uma postura análoga à do banqueiro que empresta dinheiro preocupado apenas com os resultados financeiros do empreendimento. Ele personificaria $\mathrm{o}$ ator racional dos manuais de economia. Já a prevalência do segundo tipo poderá nos induzir a pensar que a aquisição da franquia é uma espécie de estratégia de rattrapage, onde o novo comerciante paga ao franqueador uma espécie de custo de aprendizado para se estabelecer por conta própria. Uma vez aprendido o novo ofício, a tendência seria o restabelecimento do antigo padrão de pequeno burguês independente. Achamos que existe a forte possibilidade de que o segundo tipo de comportamento seja seguido mais freqüentemente por indivíduos oriundos das "nações comerciantes" (vimos alguns casos nesse sentido), mas nossos dados ainda não permitem uma conclusão mais firme. De qualquer maneira, reproduzo uma colocação do especialista em franquia, portanto, interessado na prevalência da primeira interpretação: "Nos EUA, há montes de franqueadores desse tipo (que não entendem nada do negócio franqueado o autor se refere a salões de cabeleireiro e lojas de "fast-food") Um dia perguntamos a John Amico (empresário do ramo, muito festejado nos Estados Unidos) que diabos eles tem a ver com sanduíches ou cortar cabelos e a resposta foi: 'Meu negócio não é vender sanduíches, nem cortar cabelos. Meu negócio é franquia. Do que, não me interessa" (Cherto, M., Folha de S. Paulo, coluna franquia, $14 / 11 / 94$, p. 2-2). Contrapondo-se a esse quadro, a única menção negativa ao sistema que encontrei na imprensa foi um seminário intitulado Os mitos da franquia, realizado em julho de 1994 não por acaso - na Câmara de Comércio Brasil-Israel ${ }^{18}$.

\section{A expansão e a possível crise da franquia}

Os números e sobretudo a velocidade referentes à expansão do sistema de franquia dão uma idéia da sua importância crescente: segundo estatísticas da Associação Brasileira de Franquia, o setor registrava no final de 1994 a expressiva quantia de 53 mil franqueados, contra apenas 8 mil no final 
de 1990. Do "outro lado do balcão", apareceram 1.203 empresas franqueando. A mesma fonte clama que em torno de $10 \%$ do PIB nacional passa por essa forma de negócio. Outro ponto importante, assinalando uma evolução do setor, é o número cada vez maior de empresas que oferecem franquias cujo investimento total para a instalação é inferior a cinco mil reais - como chaveiros, sapateiros e serviços de entrega a domicílio. A enorme energia social aplicada no setor fez com que atualmente tenhamos no Brasil empresas de: consultoria em preparar uma organização para se tornar franqueadora (localizamos quatro); consultoria no traçado do perfil do candidato a franqueado, para que o mesmo possa escolher o ramo de franquia em que se engajará (duas); cursos de capacitação para executivos das empresas franqueadoras (sete); escritórios de advocacia especializados em questões e contratos na área (treze); empresas de comunicação visual que trabalham exclusivamente para o segmento (uma); revistas especializadas na área (três). Anotamos também a existência de quatro Institutos e associações ditas sem fins lucrativos, que aconselham pessoas interessadas em se tornar franqueados ou franqueadores, incluindo o setor do Sebrae que mais cresce atualmente.

A rápida institucionalização do "negócio franquia" é um fenômeno evidente, criando-se em torno dele um "campo", de forma que as ações que podem por em risco a existência do sistema de forças como um todo são fortemente penalizadas. Ainda não podemos dizer muito sobre a efetividade dos mecanismos de controle disponíveis para os franqueados, mas podemos inferir alguma coisa lembrando que uma das principais características da nova situação é o papel importante da publicidade da marca franqueada diante dos possíveis compradores de franquia, e que essa publicidade se faz "boca-aboca" (os manuais do franqueado, tanto nacionais quanto norte-americanos, recomendam fortemente aos candidatos a franqueados a consulta a vários empreendedores já estabelecidos na rede de franquia que o interessado está vislumbrando) e através de órgãos de imprensa interessados na ampliação do "negócio franquia" como um todo e, portanto, dotados de alguma independência em relação a cada franqueador, inibindo dessa forma situações de grande contraste entre a situação prometida ao franqueado e a marcha efetiva dos negócios, uma vez estabelecida a franquia.

Começamos a estudar os fatores que contribuem para a robustez do produto e constatamos, entre outros pontos, o interessantíssimo "efeito-teoria" ${ }^{19}$ que é exercido pela visão do "produto franquia" como parte integrante da modernidade desejada para o Brasil, sustentada pelos economistas e jornalistas participantes do debate público (e também aqueles que, na academia, dão suporte intelectual aos nomes mais evidentes na mídia), que sustentam os "intelectuais do ramo" - revistas de franquia e pequenos negócios; colunistas especializados na mídia periódica. Num primeiro momento, esboçamos a análise do "campo simbólico-econômico" mais direto (os periódicos e colunistas especializados no assunto) que vive da franquia, principalmente através do fornecimento de consultorias e secundariamente pelo rendimento direto da

\footnotetext{
${ }^{19}$ Sobre o conceito de "efeito-teoria", cf. Bourdieu (1982, p. 100 ss.).
} 
${ }^{20}$ Inspiro-me novamente em P. Bourdieu (1977).

${ }^{21}$ Aparentemente, a formulação acima é uma versão desnecessariamente complicada da relação entre produtor e divulgador de fatos científicos em geral. Mas, no caso em que estamos trabalhando, é necessário pensar a influência do "divulgador" sobre o "produtor" de formulações econômicas. Para isso, o uso da adaptação feita por Bourdieu do modelo de Marx permite o vislumbre de relações mais complexas entre essas duas ordens de atores. Ao que tudo indica, estamos diante de uma relação de sustentação recíproca, tanto econômica quanto intelectual: simplificadamente, o desenvolvimento do circuito de educação continuada (cursos de treinamento gerencial, seminários para executivos, relatórios de uso fechado para uso no atividade periodista; e que também fazem viver o ramo, fornecendo-lhe a necessária legitimidade. Esse esforço está se revelando prometedor, mas claramente insuficiente, já que os indivíduos que se vinculam à "comunidade da franquia" como seus "intelectuais", só se sustentam nesse papel porque são secundados pelos economistas, administradores e "grandes jornalistas" citados no início do parágrafo. A lógica dessa "produção da crença" ${ }^{20}$ obedece, de alguma forma, uma mecânica análoga àquela descrita por Marx na análise da relação entre o setor produtor de bens de capital e o de bens de consumo. No nosso caso, o "bem de capital" é a "produção de idéias genéricas" sobre o rumo que deve tomar a economia e a sociedade, principalmente sobre "quais são os componentes legítimos da nova ordem"; enquanto que o "bem de consumo" consiste nas idéias específicas que referendam o campo e as posições dos atores no seu seio ${ }^{21}$.

Uma maneira interessante de observar as coalizões cognitivas e "práticas" que operam no campo está sendo fornecida atualmente pela crise econômica. A partir do final de 1995, o setor, visto como imune a crises, começou a emitir alguns sinais inquietantes. Vários franqueados e franqueadores apresentavam dificuldades e alguns faliram. Diante da novidade embaraçosa, os "intelectuais" do setor avançaram diversos tipos de explicação, interessantes pela lógica interna. Podemos agrupá-las em torno de duas posições polares: de um lado, as explicações que diziam que o problema consistia na falta de profissionalismo dos franqueadores, que vendiam franquias ou produtos mal-definidos ou mal-acabados a seus franqueados, resultando no desastre para ambos. A questão central residiria então na necessidade de uma regulação do sistema, no sentido de coibir a comercialização de franquias "amadoras". O outro grupo de explicações fazia menção à falta de preparo ou vocação dos franqueados. E, apesar de ir contra a lógica mesma do produto franquia, que promete realizar a tarefa de selecionar e preparar os franqueados, essa explicação teve mais repercussão do que a precedente. A retração de diversos mercados consumidores só poderia fazer aumentar o problema, e assim prossegue a luta pelo estabelecimento de suas causas e maneiras de superá-lo. Podemos notar que os dois tipos de explicação remetem a definições opostas também do que seria a franquia, notavelmente próximas das formulações eruditas sobre a nova forma econômica que anotamos acima. Para os campeões do primeiro grupo, mais próximo ao pensamento econômico neoclássico (no seu desenvolvimento institucional), a franquia é um tipo de negócio muito diferente do pequeno comércio tradicional, onde o pequeno investidor torna-se um especialista em contratos de franquia, aprendendo a lidar com seus negócios da mesma maneira que o banqueiro lida com os capitais: a sua ligação com a substantividade do bem ou serviço comercializado passa apenas pela rentabilidade oferecida. No segundo caso, onde é evidente a proximidade em relação à explicação dos mercadólogos ouvidos, enfatiza-se a vocação necessária para o ramo de negócio específico, donde a franquia é apenas uma forma de comercialização, que deve ser comparada a diversas 
outras. De qualquer forma, ainda que as explicações divirjam, é importante notar que em nenhum momento as dificuldades do setor foram generalizadas como sendo uma "falha sistêmica" do negócio franquia, o que, ao meu ver, demonstra a vitalidade do setor enquanto prática social legítima. Se compararmos essa apreciação implícita com aquela que aparece diante de notícias sobre, por exemplo, problemas de qualidade na prestação de algum serviço público por parte de uma agência estatal, o contraste não poderia ser mais marcante.

\section{Conclusão}

Apresentamos diversas restrições teóricas e empíricas à viabilidade do novo mundo "neoliberal". Ainda que elas possam fazer sentido, a constatação que se impõe é a da robustez do novo universo ideológico. Está firmemente estabelecido em nossa sociedade que o emprego na grande empresa é uma forma de inserção econômica em contração. As produções de sentido que davam prestígio às carreiras nas grandes empresas estão em refluxo e os grupos de indivíduos identificados com a noção popular de classe média estão sendo instados a pensar em outras formas de ganhar a vida e, sobretudo, de dar sentido a ela. Permito-me uma inferência: apesar da desvalorização evidente das perspectivas de carreira nas grandes empresas e do incentivo à inserção independente, na estabilização futura do novo "modo de regulação" deveremos ter um fluxo de pessoal intenso, e nos dois sentidos, unindo os dois setores. As antigas restriçõos ideológicas e habitualidades que separavam o pequeno empresário do gerente atenuaram-se, e muito provavelmente a pequena empresa funcionará como uma espécie de buffer de mão-de-obra gerencial para as corporações, fornecendo trabalho para as necessidades temporárias ou sazonais e absorvendo esse contingente no resto do tempo. A regulação legal para esse tipo de arranjo começa a aparecer, por exemplo, através dos contratos de trabalho temporários, em via de regulamentação no momento da conclusão deste artigo. Nesse ponto é difícil deixar de notar a congruência entre a ação governamental federal e o fatalismo do provável em termos da evolução possível das relações de trabalho.

O robustecimento do novo universo ideológico também pode ser observado por outros ângulos. De um lado, ele aparece através do conflito entre o TQC e a reengenharia, as duas possibilidades polares de vetores para a modernização empresarial, ainda que escondido pelo processo de desarmamento simbólico imposto pelos intelectuais e pela mídia em relação às possíveis percepções das linhas de força do embate. No outro lado da economia, a franquia aparece como o exemplo acabado de inserção legítima para os membros das classes médias. A análise do processo social de produção de um sentido geral para as dificuldades por que passa atualmente o emprego de longo prazo e, correlativamente, da particularização das dificuldades das novas formas aponta para a fascinante questão dos mecanismos de funciona- planejamento empresarial etc.), abre espaço para a atividade (bem) remunerada dos produtores de idéias nas empresas e associações de empresários; para atingir essa demanda, os divulgadores em geral montam as atividades e convidam os produtores, que legitimam esses últimos diante das platéias e do público consumidor de notícias empresariais em geral. A reiteração contínua desse padrão gera uma afinidade, onde a produção acaba entrando em "sintonia fina" com a divulgação. (É claro que aí ganha o senso comum em detrimento da atividade científica, vista como intrinsecamente crítica, mas talvez isso já seja ruminação nostálgica do passado dourado da atividade intelectual, e, de qualquer forma, estamos querendo fazer Sociologia e não política científica). 
mento do campo do poder no Brasil contemporâneo. Tanto no que diz respeito às operações intelectuais que sustentam a nova situação, quanto nos aspectos mais mundanos das trocas materiais que se estabelecem entre os vários participantes do "condomínio", podemos constatar que estamos falando de um jogo com um número cada vez maior de participantes, não só quantitativamente quanto no aspecto qualitativo. Nessa nova situação, o poder relativo de cada agente repousa na aquiescência dos outros membros do circuito. Isso faz com que o poder seja uma realidade cada vez mais desencarnada, impessoal, cada vez mais "um sistema", o resultado de interações múltiplas e cada vez mais difíceis de serem controladas por algum ator isolado. A constatação dessa realidade torna a tarefa da sociologia crítica muito mais complexa do que em outros tempos: de um lado, se pensarmos numa definição mínima de democracia, como um sistema de contrapeso, a situação que está se delineando torna a vida econômica e a vida pública em geral muito menos sujeita a "vontades" e a manipulações individuais. De outro lado, é bom frisar que é da lógica das sociedades individualistas a falta de interesse pelos malsucedidos. Diante da sensação de falta de alternativa à nova ordem, uma tarefa dos intelectuais passa a ser a exposição da falta de justiça nas condições de competição: a sociedade brasileira equipa seus filhos de maneira muito desigual para a "batalha da vida", e essa é uma das poucas críticas que tem possibilidade de se tornar audível nesse momento ideológico e assim produzir clamor público contra as nossas desigualdades sociais. É evidente a obsolescência dos instrumentos tradicionais de denúncia, ficando cada vez mais difícil localizar um inimigo de carne-e-osso a quem possa ser imputadas as desgraças do nosso mundo. Para sair desse impasse é necessário estudar com profundidade as relações que unem o mundo da produção de idéias com o mundo "material" sem cair na armadilha reducionista do denuncismo, que perde qualquer alcance numa sociedade cada vez mais acostumada com a injustiça.

Recebido para publicação em setembro/1997

UNITERIMS:

middle classes, neoliberalism, economical sociology, cognitive conventions, economic conventions.
ABSTRACT: The text tries to analyse recent transformations in the manner how the Brazilian middle classes perceive and signify their lives in the economic sphere. For this I make use of dates and analyses produced in researches about the transformations of the bureaucratic-work milieu, about the construction of managers' argumentative spaces, about traditional and more recent forms of

GRÜN, Roberto. Middle classes in the world of neoliberalism. Tempo Social; Rev. Sociol. USP, S. Paulo, 10(1): 143-163, may 1998. 
GRÜN, Roberto. A classe média no mundo do neoliberalismo. Tempo Social; Rev. Sociol. USP, S. Paulo, 10(1): 143-163, maio de 1998.

the small trade and about the also recent phenomenon of management unemployment. I try to understand the problem based on a study on the transformations of the cognitive conventions inherent to the way people comprehend the social world and experience the consequences of its changes in the economic sphere. The analysis shows that there exists an interesting case of institutional blindness in which all the evidences that threaten the new order are rejected and in which the old division of the middle classes between employed and autonomous strata has to be rethought.

\section{REFERÊNCIASBIBLIOGRÁFICAS}

BouRDIEU, P. (1977) La production de la croyance: contribution à une économie des biens symboliques. Actes de la Recherche en Sciences Sociales, Paris, 13, p. 3-43; retomado parcialmente em BouRdieu, P. (1996) As regras da arte. São Paulo, Companhia das Letras.

(1979) La distinction: critique sociale du jugement. Paris, Ed. de Minuit.

(1982) Ce qui parler veut dire. Paris, Ed. Fayard. Editado no Brasil como A economia das trocas linguísticas. São Paulo, Edusp, 1996. (1989) La noblesse d'État. Paris, Ed. de Minuit.

\& BolTANSKI, L. (1976) La production de l'idéologie dominante. Actes de la Recherche en Sciences Sociales, Paris, 2/3, p. 4-73.

Diebold, F. \& Neumark, D. \& Polsky, D. (1996) Comment on Kenneth A. Swinnerton and Howard Wial, "Is job stability declining in the U.S. economy?" Industrial \& Labor Relations Review, Ithaca, 49(2), jan.

Douglas, M. (1986a) How institutions think. Syracuse, Syracuse University Press.

(1986b) Smallness of scale discounted. Syracuse, Syracuse University Press.

(1992) Autonomy and oportunism. In: Risk and blame: essays in cultural theory. London \& New York, Routledge, p. 187-207.

(1996) Thought styles: critical essays on good taste. London, Sage.

EinhHorn, H. \& Hoggarth, R. (1985) Ambiguity and uncertainty in probabilistic inference. Psychological Review, Princeton, 92, p. 433-461.

FAMA, E.F. (1980) Agency problems and the theory of firm. Journal of Political Economy, Chicago, 88(2), p. 288-307.

FLIGSTEIN, N. (1990) The transformation of corporate control. CambridgeMA, Harvard University Press. 
Galbraith, J.K. (1982) O novo Estado industrial. São Paulo, Abril Cultural, cap. 6.

GiLman, S.L. (1986) Jewish self-hatred: anti-semitism and the hiddem language of the jews. Baltimore, Johns Hopkins University Press.

Goodman, N. (1978) Ways of worldmaking. Indianapolis, Hackett.

GRÜN, R. (1985) A produção de uma empresa moderna: os bancários e a automação. São Paulo, 302 p. Dissertação (Mestrado). PUC/SP. (1992) Negócios \& famílias: armênios em São Paulo. São Paulo, Ed. Sumaré/Fapesp.

(1993) Sobre o envelhecimento gerencial. Revista de Administração de Empresas da FGV, Rio de Janeiro, 33(2), p. 44-63, mar-abr. (1994) Capital \& Estado: Uma proposta de estudo do setor de papel e celulose brasileiro através da análise neo-institucional. Curitiba, Anais do XVIII Enanpad, vol. 8, p. 176-195.

(1995) A revolução dos gerentes brasileiros. São Carlos, Edufscar.

HeCKSCHER, C. (1995) White-colar blues: management loyalties in an age of corporate restructuring. New York, Basic Books.

Hopwood, A. \& Miller, P. (eds.). (1994) Accounting as social and institutional practice. Cambridge-GB, Cambridge University Press.

JACKALL, R. (1988) Moral mazes: the world of corporate managers. New York, Oxford University Press.

Johansen, R. \& Swigart, R. (1994) Upsizing the individual in the downsized organization. Reading, Addison-Wesley.

LAKOFF, G. (1996) Moral politics: what conservatives know that liberals don't. Chicago, University of Chicago Press.

MARX, K. (1971) Theories of surplus-value. Moskow, Progress Publishers, Vol. III.

MEYER, M.W. (1994) Measuring performance in economic organizations. In: SMElser, N. \& SwedBerg, R. (ed.). The handbook of economic sociology. Princeton, Princeton University Press, p. 556-579.

Montagna, P. (1990) Accounting rationality and financial legitimation. In: Zukin S.\& DiMaggio P. (eds.). Structures of capital: the social organization of economy. Cambridge-MA, Cambridge University Press, p. 227-260.

PARSONS, W. (1990) The power of economic press: journalism and economic opinion in Britain and America. New Brunswick, Rutgers University Press.

Perrow, C. (1990) Economic theories of organization. In: Zukin, S. \& Dimaggio P. (eds.). Structures of capital: the social organization 
of the economy. Cambridge-MA, Cambridge University Press, p. 121-151.

PorTer, T.M. (1995) Trust in numbers: the pursuit of objectivity in science and public life. Princeton, Princeton University Press.

REDDY, W. (1986) The structure of a cultural crisis: thinking about cloth in France before and after the Revolution. In: ApPADURAI, A. (ed.). The social life of things: commodities in cultural perspective. Berkeley, University of California Press, p. 261-284.

RIEDER, J. (1990) Rhetoric of reason, rhetoric of passion: sociolinguistic aspects of instrumental and expressive rhetorics. Rationality and Society, Thousand Oaks, 2(2), april.

SwINNERTON, Kenneth A. (1996) Is job stability declining in the U.S. economy? Reply to Diehold, Neumark, and Polsky. Industrial \& Labor Relations Review, Ithaca, 49(2), jan.

Swinnerton, Kenneth A. \& Wial, Howard (1995) Is job stability declining in the U.S. economy? Industrial \& Labor Relations Review, Ithaca, 48(2), jan.

UsEem, M. (1993) Executive defense: shareholder power \& corporate reorganization. Cambridge-MA, Harvard University Press.

Zilbovicius, M. \& Ferro, J.R \& Grün, R. (1986) Novas estratégias empresariais e novas respostas operárias: a operação Vaca Brava. Apresentado na X Anpocs, Campos de Jordão (mimeo). 